\title{
A LA BÚSQUEDA DE LA «FORMA CONDICIONANTE». INTRODUCCIÓN A LAS RELACIONES ENTRE TRIBUNALES CONSTITUCIONALES NACIONALES Y TRIBUNALES EUROPEOS DESPUÉS DEL TRATADO DE LISBOA
}

MAURIZIO PEDRAZZA GORLERO 
SUMARIO

1. RELACIONES ENTRE LOS TRIBUNALES, INTEGRACIÓN ENTRE LOS ORDENAMIENTOS Y «FORMA CONDICIONANTE» EN RELACIÓN A LA TUTELA DE LOS DERECHOS FUNDAMENTALES. 2. LA GARANTÍA DE LOS DERECHOS FUNDAMENTALES EN LOS ORDENAMIENTOS DE LA INTEGRACIÓN: LA AXIOLOGÍA ABSORBENTE Y LA FORMA CONDICIONANTE. LA TESIS QUE INDIVIDUA LA AXIOLOGÍA SUSTANCIAL PREEMINENTE INDEPENDIENTEMENTE DE LA PERTENENCIA EN EL ORDENAMIENTO Y DE LA CALIDAD FORMAL. CRÍTICA. 3. LA INHERENCIA NECESARIA DE LA FORMA CONDICIONANTE A LA AXIOLOGÍA ABSORBENTE. LAS MANIFESTACIONES DE LA FORMA CONDICIONANTE: LOS ACTOS NORMATIVOS. LAS SENTENCIAS COMO FORMA CONDICIONANTE ATENUADA. 4. LA CONCEPCIÓN SUSTANCIAL Y LA SUPERACIÓN DE LA TEORÍA DE LOS CONTRALÍMITES. CRÍTICA: LA JERARQUÍA ENTRE LOS PRINCIPIOS FUNDAMENTALES ABIERTOS O EXCLUIDOS DE REVISIÓN CONSTITUCIONAL. EL PRINCIPIO DE RIGIDEZ COMO SUPERPRINCIPIO INSTRUMENTAL EN EL ESTABLECIMIENTO DE UNA JERARQUÍA ENTRE ELLOS. EL ARTÍCULO 11 DE LA CONSTITUCIÓN COMO CLÁUSULA DE APERTURA A LA INTEGRACIÓN QUE PRESERVA LA JERARQUÍA DE LOS PRINCIPIOS CONSTITUCIONALES FUNDAMENTALES EN RELACIÓN CON EL ORDENAMIENTO EUROPEO. 5. IGUALDAD, PAZ Y JUSTICIA ENTRE LAS NACIONES. EL ARTÍCULO 11 DE LA CONSTITUCIÓN COMO SUPERPRINCIPIO FUNDAMENTAL ORDENADOR DE LA JERARQUÍA DE LOS PRINCIPIOS CONSTITUCIONALES INTERNOS OPONIBLES A LA INTEGRACIÓN EUROPEA. ¿EL ARTÍCULO 11 DE LA CONSTITUCIÓN COMO MODO DE EJERCICIO DE LA SOBERANÍA O COMO EJE PORTADOR DE LA DEMOCRACIA CONSTITUCIONAL? 6. LA TUTELA INTE- 
GRAL DE LOS DERECHOS FUNDAMENTALES EN CADA UNO DE LOS ORDENAMIENTOS DE LA INTEGRACIÓN VERSUS LAS CONCEPCIONES «ESTADIALES» O MULTINIVEL DE GARANTÍA DE LOS DERECHOS. EL CONTRALÍMITE COMO TUTELA DEL NÚCLEO ESENCIAL DE LOS DERECHOS FUNDAMENTALES. 7. LA FORMA CONDICIONANTE COMO MECANISMO NORMATIVO RESULTADO DEL ARTÍCULO 4, II, TUE Y DEL ARTÍCULO 11 DE LA CONSTITUCIÓN. EL DIÁLOGO ENTRE LA CORTE DE JUSTICIA Y LA CORTE CONSTITUCIONAL EN LA ELABORACIÓN DE LA IDENTIDAD CONSTITUCIONAL NACIONAL COMO «CONTRALÍMITE INTEGRADO». 


\title{
A LA BÚSQUEDA DE LA «FORMA CONDICIONANTE». INTRODUCCIÓN A LAS RELACIONES ENTRE TRIBUNALES CONSTITUCIONALES NACIONALES Y TRIBUNALES EUROPEOS DESPUÉS DEL TRATADO DE LISBOA
}

\author{
POR \\ MAURIZIO PEDRAZZA GORLERO \\ Catedrático de Derecho Constitucional \\ Universidad de Verona
}

1. RELACIONES ENTRE LOS TRIBUNALES, INTEGRACIÓN ENTRE

LOS ORDENAMIENTOS Y «FORMA CONDICIONANTE»EN

RELACIÓN A LA TUTELA DE LOS DERECHOS FUNDAMENTALES

Las relaciones entre los ordenamientos de la integración europea —es decir, el sistema ordinamental diseñado por las Constituciones nacionales, por los resultados del «proceso de constitucionalización» de la Unión ${ }^{2}$ y por la Convención Prado.

${ }^{1}$ Traducción del español al italiano realizada por David Delgado Ramos y Carlos Vidal

${ }^{2}$ Sobre el proceso de «constitucionalización» de la Unión Europea, cfr., entre otros, G. GRECO, Rapporti tra ordinamento comunitario e nazionale, en Trattato di diritto amministrativo europeo, 
interestatal de carácter regional custodiada por el Tribunal Europeo de Derechos Humanos ${ }^{3}$ - se caracterizan por conseguir, en el diálogo entre los «Tribunales de la integración europea» ${ }^{4}$, la conexión entre las fuentes constitutivas de cualquier sistema jurídico y los pronunciamientos jurisdiccionales que aplican las normas producidas por estas fuentes.

La identificación de esta conexión nos conduce a la solución del problema de cuáles son el orden jurídico y la instancia jurisdiccional que, ante las demandas planteadas ante los tribunales que tengan como objeto situaciones jurídicas subjetivas reconocidas y protegidas por las normas de los diferentes sistemas normativos, exhiban la «forma condicionante», es decir, en una primera aproxima-

a cargo de M.P. Chiti y G. Greco, Milán, 1997, p. 399 y ss.; M. CARTABIA, J.H.H. WEILER, L'Italia in Europa. Profili costituzionali e istituzionali, Bolonia, 2000, p. 73; F. PALERMO, La forma di Stato dell'Unione europea. Per una teoria costituzionale dell'integrazione souranazionale, Padua 2005; G. BERTI, Souranità, en Enc. dir. an-nali, I, Milán, 2008, p. 1078; A. RUGGERI, Una Costituzione ed un diritto costituzionale per l'Europa unita, en Lineamenti di diritto costituzionale dell'Unione europea, a cargo de P. Costanzo, L. Mezzetti, A. Ruggeri, Turín, 2008, p. 10 y ss.; J. TAJADURA, Constitución y democracia en la Unión Europea, en J. Tajadura y J. de Miguel (coords.), Justicia Constitucional y Unión Europea. Un estudio comparado de las experiencias de Alemania, Austria, España, Francia, Italia y Portugal, Madrid, 2008, p. 34 y ss.; R. SCARCIGLIA, La «Costituzione» europea: dal patrimonio comune al quasi-federalismo, en Diritto costituzionale comparato, a cargo de P. Carrozza, A. Di Giovine y G.F. Ferrari, Roma-Bari, 2009, p. 407 y ss. Sobre la adscribilidad de la llamada «constitución europea» a la categoría de las Constituciones contemporáneas cfr. M. DOGLIANI, Può la costituzione europea non essere una costituzione in senso moderno?, en Dem. dir., 2003, p. 80 y ss. En el sentido que, «siendo indiscutibles los perfiles de convergencia entre texto "constitucional" de la Unión y modelo estatal en cuanto a valores, derechos, criterios organizativos, queda todavía el dato incontrovertible por el que la convergencia concierne sólo los "contenidos" del documento constitucional», «a la tradicional y generalizada autolegitimación de la constitución estatal» verificando «la dependencia de aquélla de la Unión de la voluntad de los Estados constructores», cfr. G. DE VERGOTTINI, Costituzione europea, en Enc. dir. annali, I, Milán, 2007, p. 461. Igualmente cfr. R. BIN, P. CARETTI, Profili costituzionali dell'Unione europea, Milán 2008, p. 143 y ss. La carencia de «legitimación constitucional» de la Unión es evidenciada también por S. GAMBINO, Diritti fondamentali e Unione europea. Una prospettiva costituzional-comparatistica, Milán, 2009, p. 15 y ss., 19.

${ }^{3}$ Sobre los caracteres y naturaleza jurídica del Tribunal cfr., por todos, A. QUERALT JIMÉNEZ, El Tribunal de Estrasburgo: una jurisdicción internacional para la protección de los derechos fundamentales. Primeras experiencias y perspectivas de la aplicación del Protocolo n.․ำ 11 al CEDH, Valencia, 2003, p. 32 y ss.

${ }^{4}$ Así N. ZANON, Introduzione, en Le Corti dell'integrazione europea e la Corte costituzionale italiana. Avvicinamenti, dialoghi, dissonanze, a cargo de N. Zanon, Nápoles 2006, p. 1. Cfr. también M. CARTABIA, L'ora dei diritti fondamentali nell'Unione europea, en I diritti in azione. Universalità e pluralismo dei diritti fon-damentali nelle Corti europee, a cargo de M. Cartabia, Bolonia 2007, p. 13 y ss. Para un examen de las relaciones entre jueces nacionales y Tribunales de la integración europea en prospectiva comparada cfr. las contribuciones recogidas en Corti nazionali e Corti europee, a cargo de G.F. Ferrari, Nápoles, 2006. 
ción, el dispositivo formal que trazó la prevalencia de un ordenamiento sobre los otros, de una fuente y una norma sobre otras fuentes y normas, de una norma sobre los actos que la aplican.

En el recorrido que pretende alcanzar esta meta, el objeto preelegido es la tutela de las libertades fundamentales que, en cuanto simultáneamente expuestas a las protecciones y a las limitaciones de las constituciones internas, del TEDH y el derecho objetivo europeo, así como a las reconstrucciones de sus contenidos sustanciales por parte de sus respectivos Tribunales, son una prueba concluyente de las conexiones entre los ordenamientos, las fuentes y las decisiones judiciales.

Cada ordenamiento nacional conoce, de hecho, los efectos jurídicos de una serie de actos normativos de reconocimiento de los derechos fundamentales, que pertenecen a ordenamientos distintos - el mismo ordenamiento nacional, el europeo, el sistema de protección del TEDH, que están dotados (el segundo y el tercero por supuesto, sólo en parte) de los mismos elementos personales y territoriales_-, además de los resultados de la actividad jurisdiccional protectora de los derechos ejercida por los respectivos tribunales 5 .

Se trata, evidentemente, de un fenómeno que, desde la perspectiva del derecho constitucional interno, se basa en las normas que regulan la forma en que los sistemas jurídicos nacionales están abiertos al proceso de integración europea, que permitirá la influencia de la legislación europea sobre el Derecho nacional ${ }^{6}$, y

5 Sobre este punto cfr. A. RUGGERI, Composizione delle norme in sistema e ruolo dei giudici a garanzia dei diritti fondamentali e nella costruzione di un ordinamento «intercostituzionale», en "Itinerari» di una ricerca sul sistema delle fonti, XIII, Studi dell'anno 2009, Turín, 2010, p. 247 y ss.

${ }^{6}$ Cfr., por ejemplo, el artículo 11 de la Constitución Italiana; art. 23, c. 1, Grundgesetz; art. 93 Const. Española; art. 19 y 20 Const. Dinamarca; art. 93 y 95 Const. Finlandia; art. 90 Const. Polonia. Sobre este punto cfr. M. CLAES, Le «clausole europee» nelle costituzioni nazionali, en Quad. cost., 2005, p. 283 ss. En tanto que las disposiciones constitucionales disciplinan la modalidad con la que los sistemas jurídicos nacionales se abren al proceso de integración europea, permiten al derecho europeo incidir sobre el derecho nacional, también de rango constitucional. cfr. H. P. IPSEN, Als Bundesstaat in der Gemeinschaft, en E. VON CÄMMERER, H.-J. SCHLOCHAUER Y E. STEINDORFF (eds.) Probleme des Europäischen Rechts. Festschrift für Walter Hallstein zu seinem 65. Geburtstag, Frankfurt am Main, 1966, p. 254. Cfr. también A. D’ATENA, Le Regioni italiane e la Comunità economica europea, Milán, 1981, p. 5 y F. SORRENTINO, L'influenza del diritto comunitario sulla Costituzione italiana, en Studi in onore di Leopoldo Elia, II, Milán, 1999, p. 1635, 1640, 1653 ss. Sobre esto último cfr. M. NICOLINI, Partecipazione regionale e "norme di procedura». Profili di diritto costituzionale italiano ed europeo, Nápoles, 2009, p. 14 y ss., para el que la limitación de la soberanía estatal «cubierta» por las disposiciones constitucionales de «apertura» a la integración europea «han introducido cambios de relieve en el ordenamiento constitucional: basta pensar en la introducción de normas sobre producción jurídica constitutivas de un autónomo sistema de fuentes del derecho o en las innovaciones concernientes el papel de los jueces comunes y la competencia de los Tribunales Constitucionales nacionales».

(C) UNED. Revista de Derecho Político 
que, en relación con la identificación del nivel sustancial de garantías de los derechos, se caracteriza por la actitud «expansiva» de la salvaguardia de las posiciones jurídicas subjetivas tuteladas en el ámbito nacional.

El constitucionalismo democrático-social del siglo XX concibe, de hecho, sus derechos fundamentales como situaciones subjetivas capaces de activar «... un proceso de unificación y homogeneización» ${ }^{7}$ del tratamiento jurídico ubicados en varios ordenamientos. En otras palabras, es el concepto mismo de derecho fundamental el que incorpora la pretensión a la integración, es decir, la absorción de «núcleos de valores» no nacionales y a la compenetración con otros sistemas jurídicos, a fin de llegar a contenidos de protección abiertos a las contribuciones de los ordenamientos externos ${ }^{8}$.

\section{LA GARANTÍA DE LOS DERECHOS FUNDAMENTALES EN LOS ORDENAMIENTOS DE LA INTEGRACIÓN: LA AXIOLOGÍA ABSORBENTE Y LA FORMA CONDICIONANTE. LA TESIS QUE INDIVIDUA LA AXIOLOGÍA SUSTANCIAL PREEMINENTE INDEPENDIENTEMENTE DE LA PERTENENCIA EN EL ORDENAMIENTO Y DE LA CALIDAD FORMAL. CRITICA.}

En el ámbito de los derechos fundamentales y de su tutela en el sistema jurisdiccional de la integración se refleja, por tanto, la «clave» de las relaciones entre ordenamientos. En primer lugar, porque este ámbito es el lugar de la convergencia de la «constitución jurisdiccional de los derechos fundamentales» ${ }^{9}$, representada por su elaboración «pretoria» por parte del Tribunal de Justicia ${ }^{10}$ y por las sucesivas codificaciones en la Carta de Derechos Fundamentales de la Unión Europea, a la que el artículo 6.2 TUE le confiere la misma eficacia que a los Tratados ${ }^{11}$. En segundo lugar, porque esta convergencia

7 A. BALDASSARRE, Diritti della persona e valori costituzionali, Turín, 1997, p. 3.

8 Sobre este punto cfr. nuevamente A. BALDASSARRE, Diritti della persona, cit., p. 2, para el que «el artículo 2 de la Constitución no ha inaugurado un nuevo renglón de la historia de la civilización jurídica contemporánea, pero desde luego ha cerrado un paréntesis más que secular, que, a partir de las revoluciones burguesas de finales del siglo XVIII, había colocado sobre dos lugares distintos y en un relativo aislamiento recíproco los ordenamientos de la Europa continental y aquellos angloamericanos».

9 S. GAMBINO, Diritti fondamentali e Unione europea, cit., p. 72.

10 Sobre este punto cfr., recientemente, D. BUTTURINI, La tutela dei diritti fondamentali nell'ordinamento costi-tuzionale italiano ed europeo, Nápoles, 2009, p. 1 y ss.

11 Cfr. P. COSTANZO, Il riconoscimento e la tutela dei diritti fondamentali, en Lineamenti di diritto costi-tuzionale dell'Unione europea, cit., p. 372 y ss. N. PARISI, Funzione e ruolo della Carta dei 
implica también al TEDH, que, ya en la fase «pretoria» del proceso de elaboración de los derechos fundamentales se incluía — con las tradiciones constitucionales comunes - entre los «instrumentos privilegiados de la interpretación» de los derechos ${ }^{12}$.

No sólo eso. El reconocimiento y la garantía de los derechos fundamentales son comunes a todos los sistemas integrados, y es homogénea la estructura del derecho fundamental como concepto de relación entre libertad y límites aquello que varía de ordenamiento en ordenamiento, siendo la modalidad de confinamiento del derecho ${ }^{13}$ y por lo tanto, la cualidad axiológica del mismo derecho $^{14}$, debiéndose entender como prevalente la configuración del derecho en la cual cristaliza la mayor expansión del área proclamada libre respecto a los límites que se le hayan impuesto. Un lugar privilegiado, pues, desde el que observar la manera en que se identifica el ordenamiento jurídico que instituye la axiología absorbente y revela la forma condicionante que asegura la prevalencia de aquella garantía sobre otras. Forma condicionante, entonces, que concreta la atracción del nivel de salvaguardia del derecho, es decir, la consistencia de la garantía sustancial preeminente en la forma de una determinada discipli-

diritti fondamentali nel sistema delle fonti alla luce del Trattato di Lisbona, en Dir. un. eur., 2009, p. 653 y ss.; E. GIANFRANCESCO, Some considerations on the juridical value of the Charter of Fundamental Rights before and after the Lisbon Treaty, en www.forumcostituzionale.it, p. 7 y ss.

12 A. PIZZORUSSO, Il patrimonio costituzionale europeo, Bolonia, 2002, p. 26. De la CEDH como «fuente de inspiración, por el Tribunal» de justicia «para modelar una tutela comunitaria de los derechos fundamentales» hablan R. BIFULCO, M. CARTABIA, A. CELOTTO, Introduzione, en L'Europa dei diritti. Commento alla Carta dei diritti fondamentali dell'Unione europea, a cargo de R. Bifulco, M. Cartabia, A. Celotto, Bolonia, 2001, p. 13.

${ }_{13}$ Sobre el concpeto de derecho como «concepto de relación entre la actividad proclamada libre y sus confines» cfr. M. PEDRAZZA GORLERO, La costruzione della norma-parametro attraverso la definizione «per accerchiamento» (en el caso de la manifestación del pensamiento constitucionalmente tutelado), en Strumenti e tecniche di giudizio della Corte costituzionale, actas del encuentro. Trieste 26-28 mayo 1986, Milán, 1988, p. 574. Ejemplar es, bajo este punto de vista, la sentencia 2/1982 del Tribunal Constitucional español, donde se afirma que «no existen derechos ilimitados. Todo derecho tiene sus límites que, como señalaba este Tribunal en Sentencia de 8 de abril de 1981 en relación a los derechos fundamentales, establece la Constitución por sí misma en algunas ocasiones, mientras en otras el límite deriva de una manera mediata o indirecta de tal norma, en cuanto ha de justificarse por la necesidad de proteger o preservar no sólo otros derechos constitucionales, sino también otros bienes constitucionalmente protegidos».

${ }^{14}$ Sin embargo, la cualidad del área proclamada libre, «puesto que el área confinada no cambia conceptualmente al cambiar los confines», así que el concepto de derecho —y su cualidad axiológica— «acabará con identificarse con los mismos límites» (M. PEDRAZZA GORLERO, La costruzione, cit., p. 575).

(C) UNED. Revista de Derecho Político 
na del ordenamiento, la cual se convertirá así en la del ordenamiento de la integración ${ }^{15}$.

Se trata de condiciones cuya eficiencia en la dirección enunciada se pone en cuestión por un autorizado sector doctrinal ${ }^{16}$, para el que la integración entre ordenamientos no estaría sustentada por criterios formales, siendo reconducible exclusivamente a una jerarquía de valores de carácter sustancial ${ }^{17}$. Esta tesis excluye tanto la existencia de una jerarquía formal entre los ordenamientos, custodiado por «contralímites», como la posibilidad de que en un nivel de protección instituido en un ordenamiento pueda atribuirse superioridad formal sobre mecanismos de protección predispuestos por otros ordenamientos, debido a una relación de prevalencia formal entre ordenamientos y entre fuentes. Se trata de una reconstrucción de las relaciones entre ordenamientos que se mueve desde la identificación del más elevado nivel sustancial de tutela que, precisamente por ser superior, atraería hacia sí los otros grados y contenidos de garantía, independientemente del ordenamiento al que pertenecen y de la veste formal que les caracteriza ${ }^{18}$. En última instancia, la posición doctrinal examinada considera que la búsqueda de una jerarquía formal se quedaría sin objeto, y no subsistiría una forma predeterminada indicativa de la prevalencia de una garantía sobre otra.

A esta posición se le puede objetar que la identificación de la axiología absorbente no puede separarse del descubrimiento de la forma que la contiene y la hace valer y que es (o se convierte en) la «máscara» de su preeminencia axiológica. La forma, en efecto, es necesaria para manifestar y dar a conocer la calidad absorbente y el carácter condicionante de la axiología. El nivel sustancial más elevado de protección del derecho, entonces, se convierte en una fuente formal, sin la cual la hermenéutica, que en ese nivel busca una actitud absorbente, quedaría privada del propio objeto, como un ciego al que se impide tocar un rostro y reconstruir la expresión a través del tacto.

15 En la acepción que a tal expresión da F. PALERMO, La forma di Stato dell'Unione europea, cit., p. 5, refiriéndose al «derecho de la integración... para indicar no un ordenamiento específico ... pero la disciplina de las relaciones constitucionales entre la Unión Europea y los Estados miembros; una disciplina fragmentaria que necesita de la reconstrucción sistemática componiendo las teselas de un mosaico y que produce ... un derecho diverso pero recíprocamente compatible entre los Estados y la Unión».

${ }^{16}$ Cfr. A. RUGGERI, Sistema integrato di fonti, tecniche interpretative, tutela dei diritti fondamentali, en Pol. dir., 2010, p. 3 y ss.

17 Cfr. A. RUGGERI, Sistema integrato, cit., p. 17.

18 Cfr. A. RUGGERI, Corte costituzionale e Corti europee: il modello, le esperienze, le prospettive, Seminario de Pisa sobre Corte costituzionale e sistema istituzionale, Pisa 4-5 junio 2010, paper, p. 1 y ss. 


\section{LA INHERENCIA NECESARIA DE LA FORMA CONDICIONANTE A LA AXIOLOGÍA ABSORBENTE. LAS MANIFESTACIONES DE LA FORMA CONDICIONANTE: LOS ACTOS NORMATIVOS. LAS SENTENCIAS COMO FORMA CONDICIONANTE ATENUADA}

La forma condicionante que ordena este tipo de relaciones axiológicas entre los sistemas jurídicos de protección de los derechos se puede situar en cada uno de los ordenamientos de la integración europea. Se podría incluso decir que, por razones de carácter histórico y por la ya mencionada propensión del constitucionalismo del siglo XX a brindar protección plena a los derechos fundamentales dentro de cada ordenamiento jurídico, la axiología absorbente se encuentra, en primer lugar, dentro de cada orden constitucional en los que se alza como contralímite $^{19}$, siendo capaz de romper la jerarquía formal entre ordenamientos cuando el contralímite sea invocado frente a un ordenamiento preeminente. De ello se deduce que la axiología absorbente y la forma condicionante no se coloquen necesariamente en el ordenamiento prevalente: incluso es posible, como es el caso en las relaciones entre los Estados miembros y la Unión Europea, que sea el mismo ordenamiento europeo el que señale como absorbente la axiología de los ordenamientos nacionales, remitiéndose a su «identidad constitucional» para determinar el nivel de protección «integrado» de un derecho de libertad (artículo 4 c. II, TUE).

De una cosa, sin embargo, se puede estar seguro, que la primacía axiológica siempre se incardina dentro de una forma y aquella forma sostiene y guía la tutela de la libertad en la relación entre los ordenamientos.

$\mathrm{Si}$, por otra parte, conjurando el problema de la forma (esta «piel sin extremidades», que gozaría de consideración separada del cuerpo con el único objetivo de negarle la capacidad de revelarlo) se quisiese considerar que sea el juez quien

19 Sobre los controlímites cfr. P. BARILE, Ancora su diritto comunitario e diritto interno, en Studi per il vent-simo anniversario dell'Assemblea Costituente, VI, Autonomie e garanzie costituzionali, Florencia 1969, p. 45.; M. MANETTI, I principi costituzionali come principi supremi, en Giur. cost., 1983, p. 1130 y ss.; F.P. CASA-VOLA, I principi supremi nella giurisprudenza della Corte costituzionale, en Foro it., 1995, IV, c. 153 y ss.; A. SPADARO, Dalla Costituzione come «atto» (puntuale nel tempo) alla Costituzione come «processo» (storico). Ovvero della continua evoluzione del parametro costituzionale attraverso i giudizi di costituzionalità, en Quad. cost., 1998, p. 374; F. MODUGNO, I principi costituzionali supremi come parametro nel giudizio di legittimità costituzionale, en Il principio di unità del controllo sulle leggi nella giurisprudenza della Corte Costituzionale, a cargo de F. Modugno, A. S. Agrò y A. Cerri Turín 1997, p. 292 y ss; R. CALVANO, Il ruolo dei principi fondamentali della Costituzione nella giurisprudenza costituzionale, en Giurisprudenza costituzionale e principi fondamentali. Actas del Convenio anual del «Grupo de Pisa» Capri, 3-4 junio 2005, a cargo de S. Staiano, Turín 2006, p. 371 y ss.

(C) UNED. Revista de Derecho Político 
determine la prevalencia de un contenido sustancial de garantía, se podría recordar que la sentencia no da sólo la solución de un caso concreto, sino que implícitamente plantea la regla que permitió la solución de este caso y por tanto una regla abierta a la aplicación a todos los casos concretos análogos que se producirían en el ordenamiento. En otras palabras, también los procesos jurisdiccionales pueden venir reconducidos al carácter de la generalidad-abstracción propio de las normas y de las fuentes ${ }^{20}$. Se abstraen de la «res judicanda», de la cual son una simple solución, puesto que proponen un modelo de acción que debe ser replicado en el ordenamiento cuando lo requiera la igualdad, entendida como una aplicación razonable del principio de derecho enunciado por el juez ${ }^{21}$.

El razonamiento desarrollado para las fuentes debe, así, extenderse a las decisiones judiciales, que se convierten, también, en formas condicionantes. Basta pensar en la labor del Tribunal de Justicia, que ha precisado los derechos fundamentales, convirtiéndolos en un principio general del Derecho comunitario para, a continuación, codificar este tipo de fuente de producción del derecho objetivo europeo (con especial referencia a la protección de los derechos fundamentales) como establece el Art. 6, II, del TUE, introducido por el Tratado de Maastricht, modificado posteriormente por el Tratado de Lisboa ${ }^{22}$. Sus sentencias, deudoras (debido a la ausencia de documentos escritos hasta la Carta de Derechos Fundamentales) de una concepción selectiva y casuística, di-

20 Sobre la «generalidad en sentido temporal, como repetición ... de la norma» que se resuelve en la abstracción, o mejor en uno de los aspectos bajo los cuales es posible hablar de abstracción», cfr. V. CRI-SAFULLI, Lezioni di diritto costituzionale, I, Introduzione al diritto costituzionale italiano (Gli ordinamenti giuridici — Stato e costituzione — Formazione della Repubblica italiana), Padua 1970 , p. 21 y p. 22 sobre la reconducibilidad de las decisiones jurisdiccionales al paradigma de la abstracción. Por otro lado, «también el proceso y la sentencia (de las que la norma debería diferenciarse) son —en cuanto reconducibles a casos concretos (según la apariencia del hecho: species facti) en algún modo abstractos», se tiene un «alargamiento del concepto de norma, por el que se darían normas más o menos abstractas, a las menos abstractas, atribuyéndose por convención los caracteres del proceso y de la sentencia» (M. PEDRAZZA GORLERO, Il patto costituzionale. Potere e diritto tra prote-zione ed obbedienza, Padua, 2009, p. 145).

21 No muy distintas de las leyes procesales, respecto de las cuales puede decirse que, «mientras que la ley meramente formal pone, a través del contacto sistemático con el principio de igualdad, la norma del procedimiento que la sustancia y el acto administrativo que la presupone, pero no la regla que lo concierne» (M. PEDRAZZA GORLERO, Le fonti dell'ordinamento repubblicano, Milán, 2010, p. 94).

${ }^{22}$ Cfr. el vigente art. 6,III, TUE. Sobre este punto cfr. N. PARISI, Funzione e ruolo della Carta dei diritti, cit., p. 675 y ss. Sobre la reconducción, por parte del Tribunal de Justicia, de la tutela de los derechos fundamentales a los principios generales del derecho europeo y sobre la introducción del artículo 6, II, TUE, cfr. A. PIZZORUSSO, Il patrimonio, cit., p. 17 y ss. 
señaron la esfera de ejercicio de los derechos de libertad, además de las distintas relaciones libertad-límites ${ }^{23}$. Es más, la delimitación pretoria de los derechos ha adquirido una relativa estabilidad desde el momento en el que el Tribunal de Justicia ha utilizado su doctrina precedente. En ese sentido, todavía se habla de un modelo de garantía de los derechos fundamentales supranacionales, alimentado por una jurisprudencia que posee elementos y orientaciones homogéneos y consolidados ${ }^{24}$.

Por otra parte, en apoyo del carácter de la forma condicionante de los procesos judiciales, se puede recordar que el Tribunal Constitucional italiano ha ampliado a las sentencias del Tribunal de Justicia la capacidad de producir efectos directos, igualmente que las disposiciones de los Tratados y directivas de la auto-ejecución ${ }^{25}$. De igual modo que tales actos normativos, los principios establecidos en las decisiones del Tribunal de Justicia «se insertan directamente en el ordenamiento interno», ya que se les reconoce «valor de jus superveniens», que condiciona y determina los límites dentro de los que la norma europea inter-

23 Sobre este punto cfr. D. BUTTURINI, La tutela dei diritti fondamentali nell'ordinamento costituzionale italiano ed europeo, Nápoles, 2009, p. 43.

${ }^{24}$ Cfr. Tribunal de Justicia, 12 noviembre 1969, c.-29/69, sent. Erich Stauder contro città di Ulm-Sozia-lamt, en Raccolta, 1969, p. 415 y ss.; Tribunal de Justicia, 17 diciembre 1970, c.-11/70, sent. Internationale Handelsgesellschaft MBH contro Ein-fubrund Vorratsstelle für Getreide und Futtermittel, en Raccolta, 1970, p. 1125 y ss.; Tribunal de Justicia, 14 mayo 1974, c.-4/73, sent. Nold, Koblen und Baustoffgrosshandlung contro Commissione delle Comunità europee, en Raccolta, 1974, p. 491 y ss.; Cfr. Tribunal de Justicia, 13 diciembre 1979, c.-44/79, sent. Liselotte Hauer contro Land Rheinland-Pfalz, en Raccolta, 1979, p. 3727 y ss. Sobre este punto cfr. M. CARTABIA, L'ora dei diritti fondamentali nell'Unione Europea, cit., p. 15 y ss.

25 Esta actitud ha estado reconocida, en un primer momento, a las sentencias interpretativas pronunciadas como consecuencia de una cuestión prejudicial por parte de los jueces ordinarios: cfr. Tribunal Constitucional italiano, sent. n. 113/1985, en Giur. cost., 1985, I, p. 694 y ss. Posteriormente, el Tribunal Constitucional ha confirmado la propia posición, confiriendo al principio de la «inmediata aplicabilidad de una normativa comunitaria en la interpretación de una sentencia del Tribunal de Justicia en un juicio instaurado en el sentido del artículo 177 [ahora 267] del Tratado». Si, de hecho, concierne al Tribunal de Justicia «asegurar el respeto al derecho de la integración y en la aplicación del ... Tratado, se debe deducir que cualquier sentencia que aplica y/o interpreta una norma comunitaria tiene indudablemente un carácter de sentencia declarativa del derecho comunitario, en el sentido de que el Tribunal de Justicia, como intérprete cualificado, precisa el significado con las propias sentencias y, por esa vía, se determina, en definitiva, el contenido de las posibilidades aplicativas». Cuando, entonces, el principio viene referido a una norma europea con efectos directos, «non hay duda de que la precisión o la integración del significado normativo completado a través de una sentencia declarativa del Tribunal de Justicia tienen la misma e inmediata eficacia de las normas interpretadas» (Tribunal Constitucional italiano, sent. n. 389/1989, en Giur. cost., 1989, I, p. 1765). Cfr., sobre este punto, M. PEDRAZZA GORLERO, Le fonti del'ordinamento repubblicano, cit., p. 58 y ss.

(C) UNED. Revista de Derecho Político 
pretada debe ser aplicada por el juez nacional ${ }^{26}$. Se trata, de hecho, de una extensión a las decisiones del Tribunal de Justicia de los mismos efectos que la norma confiere a los reglamentos en razón de su carácter formal. La estabilidad, en este caso, no es de naturaleza sustancial (no se atiene, pues, al contenido de la forma condicionante dado que el ordenamiento europeo no conoce el principio del stare decisis et non quieta movere ${ }^{27}$ ), pero afecta al mecanismo de introducción de los efectos jurídicamente vinculantes dependientes de la interpretación de los actos normativos por parte del juez europeo.

En este sentido, la operación interpretativa realizada por el Tribunal de Justicia e inmersa en la legislación italiana a través de los mecanismos formales establecidos por el Tribunal Constitucional, sigue la relación entre las normas que se suceden en el tiempo: la decisión posterior circunscribe la eficacia de la interpretación judicial precedente de ese acto, produciendo un efecto similar a la derogación. En última instancia, aún así, se confirma que las sentencias, como las fuentes, concretan la forma condicionante. Un condicionamiento en cierta medida «atenuado», porque la forma en la que la sentencia se resuelve es, en realidad, condicionante sólo si debe ser recreada como una regla para casos futuros, pero esto no sucede en la legislación italiana, ni en los sistemas jurídicos de civil law de los Estados miembros ${ }^{28}$.

${ }^{26}$ Tribunal Constitutional italiano, ord. n. 62/2003, en Giur. cost., 2002, p. 590.

27 Para un mayor análisis, se remite a M. PEDRAZZA GORLERO, Introduzione a una ricerca sul precedente nella giurisprudenza della Corte costituzionale, en Il precedente nella giurisprudenza della Corte costituzionale, a cargo de M. Pedrazza Gorlero, Padua, 2008, p. 1 y ss., 7 y ss.

${ }^{28}$ En ese sentido cfr. F. GALGANO, Il precedente giudiziario in civil law, en Atlante di diritto privato comparato, a cargo de F. Galgano, con la colaboración de F. Ferrari y G. Ajani, Bolonia, 2006, p. 29 y ss. y 32 para la afirmación según la cual los derechos de los Lores británicos, en el caso Fothergill v Monarch Airlines Ltd [1980] APP.L.R. 07/10, «debe hacer referencia al derecho vigente en un país de civil law, se encuentren de acuerdo para tener en cuenta la doctrina continental en lugar de su voluble jurisprudencia». 
4. LA CONCEPCIÓN SUSTANCIAL Y LA SUPERACIÓN DE LA TEORÍA DE LOS CONTRALÍMITES. CRÍTICA: LA JERARQUÍA ENTRE LOS PRINCIPIOS FUNDAMENTALES ABIERTOS O EXCLUIDOS DE REVISIÓN CONSTITUCIONAL. EL PRINCIPIO DE RIGIDEZ COMO SUPERPRINCIPIO INSTRUMENTAL EN EL ESTABLECIMIENTO DE UNA JERARQUÍA ENTRE ELLOS. EL ARTÍCULO 11 DE LA CONSTITUCIÓN COMO CLÁUSULA DE APERTURA A LA INTEGRACIÓN QUE PRESERVA LA JERARQUÍA DE LOS PRINCIPIOS CONSTITUCIONALES FUNDAMENTALES EN RELACIÓN CON EL ORDENAMIENTO EUROPEO

Desde otra perspectiva, el diseño axiológico-sustancial somete a una crítica radical a la teoría de los contralímites. Esta teoría, elaborada por la literatura y desarrollada por las jurisdicciones constitucionales nacionales ${ }^{29}$ como límite a las limitaciones de soberanía, debería considerarse superada porque llevaría al absurdo lógico-jurídico de que las «cláusulas europeas» ${ }^{30}$, contenidas en las constituciones nacionales, las cuales dan cobertura al proceso de integración europea —en Italia, el artículo 11 de la Constitución_-, siendo expresivas de un principio fundamental del ordenamiento constitucional, en el momento de la oposición del contralímite, vendrían a decaer frente a otros principios también fundamentales, activando una relación de jerarquía formal entre los principios fundamentales todos constitutivos de la forma de Estado.

A esta tesis se puede sin embargo replicar que no se puede negar una jerarquía interna entre principios en el ordenamiento constitucional, que supraordina algunos de carácter fundamental sustrayéndolos a la revisión, principios dotados de un grado de eficacia superior al de las otras normas constitucionales, aun formando parte todos del mismo rango normativo. Y se debe también admitir un principio de jerarquía entre principios fundamentales, el de la rigidez, necesariamente supraordinado a los otros en cuanto instrumento que supone su resistencia a la revisión. Un límite a la mayoría gobernante que ha sido «legado» como autolímite por la mayoría constituyente ${ }^{31}$. Pero entonces, ¿cómo es posible que una li-

${ }^{29}$ En particular, los Tribunales Constitucionales italiano y alemán: sobre este punto cfr. M. CARTABIA, Ordinamento comunitario e sovranità nazionale in una sentenza del Bundesverfassungsgericht, en Giur. cost., 1988, II, p. 191 ss.; F. DONATI, Diritto comunitario e sindacato di costituzionalità, Milán, 1995, p. 45 y ss.; A. CELOTTO, Italia, en Justicia constitucional, cit., p. 217 y ss.

30 Tomando la expresión utilizada por M. CLAES, Le «clausole europee», cit., p. 283 y ss.

31 Sobre este punto cfr., M. DOGLIANI, Potere costituente e revisione costituzionale, en Quaderni costituzionali, 1995, p. 7 y ss. y M. PEDRAZZA GORLERO, Il patto costituzionale, cit. p. 78 y ss. 
mitación a las limitaciones de la soberanía interna en el ordenamiento jurídico italiano no se extienda a las relaciones con el ordenamiento supranacional? Esto es, que respecto de los principios fundamentales excluidos de revisión —entre los que también se incluye el impuesto por el artículo 11 de la Constitución- se dé la máxima resistencia interna y la máxima aceptación externa.

Se sabe cómo ha repondido la sentencia número $1146 / 1988^{32}$, en la que el Tribunal Constitucional italiano ha elaborado la categoría de los «principios supremos del ordenamiento constitucional» como límites implícitos a la revisión, recordando la propia jurisprudencia sobre las relaciones entre el ordenamiento italiano y los ordenamientos externos ${ }^{33}$. Sería contradictorio que el Estado no impusiese a las leyes de revisión el cumplimiento de los principios que ha individuado como límites infranqueables de las normas concordatarias ${ }^{34}$, las comunitarias $^{35}$ y las del «derecho internacional generalmente reconocidas ${ }^{36}$, que son idóneas para vincular al ordenamiento italiano debido a las limitaciones de la soberanía aceptadas según los artículos 7.2, 11 y 10.1 de la Constitución, es decir, que el legislador puede revisar más de lo permitido a los ordenamientos en relación con los cuales el Estado italiano limita su soberanía al más alto grado, exigiendo sólo el respeto de un núcleo «limitado» de principios intangibles ${ }^{37}$.

En última instancia, los principios fundamentales no están todos ubicados en el mismo plano: en el interior del ordenamiento se da, de hecho, una jerarquía entre ellos que, a través de la cláusula de apertura en el proceso de integración, se puede oponer al ingreso del derecho europeo. El principio fundamental del artículo 11 de la Constitución, entonces, no cede a los contralímites que a su vez pueden oponerse al ordenamiento europeo, pero, como la rigidez, que conserva los principios básicos dentro del orden constitucional, representa el «superprincipio» que extiende la conservación al ámbito de los ordenamientos externos ${ }^{38}$.

32 Cfr. Giur. Cost., 1988, I, p. 5565 y ss., con nota de S. BARTOLE, La Corte pensa alle riforme istitu-zionali?

33 Corte cost., sent. n. 1146/1988, cit., p. 5569.

34 Cfr., entre otras, Corte costituzionale, sent. n. 30/1971, en Giur. cost., 1971, p. 153; Corte cost., sent. n. 31/1971, ibid, p. 155; Corte costituzionale, sent. n. 18/1982, ibid, 1982, I, p. 138 y ss. especialmente p. 180 y ss., con comentario de R. NANIA, Il Concordato, i giudici, la Corte.

35 Corte costituzionale, sent. n. 183/1973, cit., p. 2420.

36 Corte costituzionale, sent. n. 48/1979, en Giur. cost., 1979, p. 373 y ss.

37 Cfr. F. DONATI, Diritto comunitario e sindacato di costituzionalità, cit., p. 21.

38 Sobre este punto cfr. F. MODUGNO, I principi costituzionali supremi come parametro nel giudizio di legitti-mità costituzionale, en Il principio di unità del controllo sulle leggi nella giurisprudenza della Corte Costituzionale, a cargo de F. Modugno, A. S. Agrò y A. Cerri Turín 1997, p. 292 y ss. Sobre el concepto de «núcleo duro» de la Constitución cfr. también A. SPADARO, Dalla Costituzione come 
Ciertamente, se puede convenir que una jerarquía formal entre los principios fundamentales pueda configurarse como una barrera a la integración, donde se conciba el contralímite, expresivo de tal jerarquía, desde una óptica puramente «defensiva» del patrimonio constitucional nacional ${ }^{39}$. Pero esta no es la función asignada a los contralímites, especialmente después del Tratado de Lisboa, que, como ya se ha señalado ${ }^{40}$, ha incorporado al artículo 4.II, TUE, los principios constitucionales y la identidad constitucional de los Estados miembros, —a saber, aquellos que tienen naturaleza de contralímites - en el ámbito del ordenamiento europeo ${ }^{41}$.

Los contralímites se caracterizan, más bien, por circunscribir el perímetro dentro del que se da la prevalencia del derecho europeo sobre el interno, produciendo una concurrencia asimétrica en las relaciones entre normas europeas y principios supremos del ordenamiento constitucional. La asimetría estaría determinada por el carácter condicionado de la prevalencia, consecuencia de la diferente modulación de las relaciones entre el derecho europeo y el derecho constitucional nacional. La concurrencia se resuelve con la integración, en todos los casos en los que las normas europeas no reduzcan los ámbitos de aplicación de las garantías constitucionales intangibles. Si por el contrario tal concurrencia, desde el lado del ordenamiento europeo, introduce normas que violan los niveles nacionales cuya reducción es inasumible, representados por los derechos inalienables de la persona humana y los principios fundamentales del orden constitucional, emerge de nuevo la separación como regla de las relaciones entre el derecho europeo y derecho interno. En otras palabras, la concurrencia se retrae puesto que se convierte en separación. La separación será activada concretamente por el instituto del contralímite, que tiene la función de reposicionar el ordenamiento jurídico interno como ordenamiento distinto respecto del europeo, desactivando la disposición a la integración con este último. Las garantías constitucionales intangibles diseñan, por tanto, el terreno en el que se explica la eficacia «superior» del ordenamiento europeo, operando, en caso de homogeneidad entre garantías supranacionales,

\footnotetext{
«atto» (puntuale nel tempo) alla Costituzione come «proces-so» (storico). Ovvero della continua evoluzione del parametro costituzionale attraverso i giudizi di costituziona-lità, en Quaerni. cosituzionale., 1998, p. 374.

39 Cfr. supra, $\S 2$.

40 Sobre el papel negativo y defensivo de los contralímites cfr. M. CARTABIA, Principi inviolabili e integr-zione europea, Milán 1995, p. 128 y ss.

41 En el sentido de que la cláusula de salvaguardia de las identidades constitucionales implicaría la «europeización» de la doctrina de los contralímites cfr. A. RUGGERI, Integrazione europea e ruolo delle autonomie territoriali (lineamenti di un «modello» e delle sue possibili realizzazioni), en "Itinerari» per una ricerca sul sistema delle fonti, IX, Studi dell'anno 2005, Turín, 2006, p. 471 y ver nota 8 .
} 
como presupuesto para la integración entre ordenamientos, y, por el contrario, como fundamento de la separación, en el caso de que las normas europeas entren en contradicción con ellas ${ }^{42}$.

5. IGUALDAD, PAZ Y JUSTICIA ENTRE LAS NACIONES. EL ARTÍCULO 11 DE LA CONSTITUCIÓN COMO SUPERPRINCIPIO FUNDAMENTAL ORDENADOR DE LA JERARQUÍA DE LOS PRINCIPIOS CONSTITUCIONALES INTERNOS OPONIBLES A LA INTEGRACIÓN EUROPEA. ¿EL ARTÍCULO 11 DE LA CONSTITUCIÓN COMO MODO DE EJERCICIO DE LA SOBERANÍA O COMO EJE PORTADOR DE LA DEMOCRACIA CONSTITUCIONAL?

Sin embargo, cabría objetar que, elevando a contralímites los principios fundamentales del ordenamiento constitucional asociados a la jerarquía de eficacia que los ordena en relación con el proceso de integración europea, el ordenamiento constitucional estaría habilitado para oponer a la integración - como contralímites - cualquier principio fundamental. Esto porque, siendo inherentes los principios fundamentales al rango normativo de la «constitución nuclear» ${ }^{43}$, es decir, esa zona de la Constitución en la que se recogen tales principios excluidos de revisión, la individuación de los contralímites, cuando también se les atribuyese una función regulativa de la «competencia asimétrica» entre ordenamientos, se aprovecharía de un criterio de selección, por así decirlo, «de manga ancha», y como tal libremente plasmable (por el legislador y) por el Tribunal Constitucional ${ }^{44}$.

Será conveniente, por tanto, verificar cuáles son los contralímites efectivamente oponibles a la integración europea; si hay, por ejemplo, un principio constitucional que es capaz de identificar los mismos contralímites. En otras pa-

42 M. PEDRAZZA GORLERO, Le fonti dell'ordinamento repubblicano, cit., p. 48 y ss. Sobre el fenómeno por el que los contralímites inciden según una actitud de integración y/o separación entre ordenamientos, según que estén en juego los principios supremos intangibles del ordenamiento constitucional, cfr. D. BUTTURINI, La tutela dei diritti fondamentali, cit., p. 65 y ss.

43 Se trata de la llamada «superconstitución o constitución "nuclear"», es decir, el «núcleo constitucional representado por la norma sobre el procedimiento de revisión constitucional y por las normas que establecen elementos explícitos o implícitos (en particular el de la rigidez) a la hora de operar la rigidez». (M. PEDRAZZA GORLERO, Le fonti dell'ordinamento repubblicano, cit., p. 73).

44 Así, A. RUGGERI, Sistema integrato di fonti e sistema integrato di interpretazioni, nella prospettiva di un'Europa unita, infra, en PEDRAZZA GORLERO, M .(ed.), Corti costituzionali e Corti europee dopo il Trattato di Lisboa, Nápoles, 2010, § 2, pp. 25-65. 
labras, cuáles son los «ulteriores» principios, en el área de la constitución nuclear, capaces de contener la noción de principio fundamental con objeto de valorar su posible oposición al ordenamiento europeo.

Lo que establece el mecanismo regulador de la relación entre ordenamiento italiano y ordenamiento europeo, haciendo accionable el contralímite es, evidentemente, el artículo 11 de la Constitución, que concreta el límite a las limitaciones de soberanía a favor de un ordenamiento jurídico-político supranacional dirigido a asegurar la paz y la justicia entre las naciones ${ }^{45}$.

Es por tanto en tal disposición cuando es posible identificar los parámetros de legitimidad de los contenidos de los contralímites y, por tanto, de los principios supremos del ordenamiento constitucional italiano, entre los cuales, en particular, está el principio de la inviolabilidad de los derechos fundamentales de la persona humana, reconocidos y garantizados al individuo, sea singularmente o en las formaciones sociales en las que se desarrolla su personalidad ${ }^{46}$. Más concretamente, el contralímite nacional no podrá alegarse — y generar la «separación»donde se encuentra con los requisitos, de procedimiento y de fondo, de la «cláusula europea» del artículo 11 de la Constitución: la igualdad, deducible de las modalidades de transferencia de la soberanía — reciprocidad y carácter paritario--, que reproduce la igualdad de los ciudadanos en la titularidad y el ejercicio de la soberanía popular (artículos 1.2 y 48 de la Constitución), las limitaciones de la soberanía para el establecimiento de una organización supranacional, dirigida al logro de esos objetivos (de paz y la justicia) que, a través del artículo 11 de la Constitución se trata de lograr ${ }^{47}$.

45 Sobre esto, cfr. V. CRISAFULLI, Lezioni di diritto costituzionale, II, 1, L'ordinamento costituzionale ita-liano (Le fonti normative), a cargo de F. Crisafulli, Padua, 1993, p. 171; A. CASSESE, sub Art. 11, en Comm. Cost., diretto da G. Branca, Principi fondamentali. Art. 1-12, Bolonia-Roma, 1975, p. 577 y ss.; G. SPERDUTI, Sulle «limitazioni di sovranità» secondo l'articolo 11 della Costituzione, en Riv. trim. dir. pubbl., 1978, p. 473 y ss.; M. CARTABIA, L. CHIEFFI, sub Art. 11, en Comm. Cost., a cargo de R. Bifulco, A. Celotto, M. Olivetti, I, Art. 1-54, Turín, 2006, p. 266.

46 Para una reconstrucción del artículo 2 de la Constitución cfr. A. BARBERA, sub Art. 2, en Comm. Cost., a cargo de G. Branca, Principi fondamentali, cit., p. 50 y ss. Para un examen del concepto de inviolabilidad de los derechos a la luz del artículo 2 de la Constitución. cfr. A. BALDASSARRE A., Diritti inviolabili, en Enciclopedia giuridica, XI, Roma, 1989, p. 1 y ss.; A. PACE, Problematica delle libertà costituzionali. Parte generale, Padua, 2003, p. 41 y ss.

47 Sobre los requisitos según los que el art. 11 de la Constitución permite efectuar cesiones del ejercicio de la soberanía interna para la finalidad y los objetivos indicados cfr., A. CASSESE, sub Art. 11, cit., p. 565 y ss. En el sentido de que la autolimitación de soberanía realizada en «forma contractual colectiva»y en «condiciones de recíproca paridad» comporta la transferencia del ejercicio - pero no de la titularidad- de los poderes soberanos cfr. A. MANZELLA, Lo Stato «comunitario», en Quaderni cosituzionali., 2003, p. 273 y ss.

(C) UNED. Revista de Derecho Político 
El artículo 11 de la Constitución opera, por lo tanto, como un puente entre la axiología interna en el ordenamiento nacional y la externa propia del ordenamiento europeo, es decir, como una «filtro» a la luz de la cual conducir el examen de compatibilidad de los contralímites con los principios fundamentales de la igualdad, la paz y la justicia. En cuanto «filtro» de oponibilidad de los valores constitucionales al proceso de integración europea, el artículo 11 de la Constitución viene, en buena medida, a constituir el superprincipio fundamental ordenador de la jerarquía de los principios fundamentales internos oponibles al proceso de integración europea.

El artículo 11 de la Constitución se convierte así no tanto en la disposición mediante la que se ejercita la soberanía, en el sentido del artículo 1 de la Constitución, en las formas y en los límites allí contemplados, sino en el eje portador de la "democracia constitucional» ${ }^{48}$, en torno al cual se mueve la entera organización del Estado, activando formas y límites ulteriores al ejercicio de la soberanía, como aquellos que derivan del hecho de que a través de ella se establece un ordenamiento jurídico preeminente sobre el estatal.

A la luz de estas consideraciones, si el superprincipio del artículo 11 de la Constitución viene a fundar tanto la soberanía interna cuanto a constituir y a informar a los mismos valores de la soberanía externa, es obvio que la diferencia entre los contralímites y los principios fundamentales sobre los que se funda la Unión Europea se «difumina», y los principios de estructura del ordenamiento italiano y del europeo a fluyen los unos dentro de los otros ${ }^{49}$. En otras palabras: el artículo 11 de la Constitución constituye la «forma condicionante» de la axiología del ordenamiento italiano y, en razón de los objetivos que esta disposición trata de alcanzar —objetivos que son los mismos sobre los que se fundamenta el ordenamiento europeo- coloca la «clave» (la sustancia, podría decirse) de la propia forma condicionante en la preeminencia misma del ordenamiento europeo. Tampoco parece que haya contradicción en esta conclusión, dado que, por un lado, el «patrimonio genético» de los ordenamientos nacionales se comunica al ordenamiento europeo y, por otro lado, la identidad de valores situados en la base de las relaciones entre ordenamientos es común y se desvela, como ya se ha dicho y se verá más adelante,

48 Según la feliz intuición de V. ONIDA, La Costituzione, Bolonia 2007, p. 23.

49 Piénsese, por ejemplo, en la remisión a las tradiciones constitucionales comunes como instrumentos privilegiados de interpretación en materia de derechos fundamentales y en el respeto de la identidad constitucional nacional al que el ordenamiento europeo se vincula en virtud del artículo 4 TUE. Sobre estel punto cfr. E. BINDI, Tradizioni costituzionali comuni e valore del Trattato costituzionale europeo, en Giurisprudenza costituzionale e principi fondamentali, cit., p. 533 y ss. 
por el artículo 4 del $\mathrm{TUE}^{50}$. La preeminencia del ordenamiento europeo es, por tanto, de naturaleza formal, aunque el contenido axiolólogico que le corresponde puede ser propio del ordenamiento europeo o bien derivado en su totalidad o en parte de otro ordenamiento de la integración. En tales casos, la preeminencia se manifiesta, bajo el perfil sustancial, como una cualidad de la relación entre los ordenamientos, que puede activar de modo diverso las relaciones de separación/integración entre los ordenamientos italiano y europeo sobre la base del artículo 11 de la Constitución, que dicta la norma genética del ordenamiento europeo y la norma de reconocimiento de la relativa producción normativa ${ }^{51}$.

\section{LA TUTELA INTEGRAL DE LOS DERECHOS FUNDAMENTALES EN CUALQUIERA DE LOS ORDENAMIENTOS DE LA INTEGRACIÓN VERSUS LAS CONCEPCIONES «ESTADIALES»O MULTINIVEL DE GARANTÍA DE LOS DERECHOS. EL CONTRALÍMITE COMO TUTELA DEL NÚCLEO ESENCIAL DE LOS DERECHOS FUNDAMENTALES}

Un sistema de relaciones entre los sistemas jurídicos basados en contactos axiológicos no formalizados no es capaz de garantizar la seguridad en la protección de los derechos fundamentales, mientras la identificación del artículo 11 de la Constitución como «forma condicionante» que, de un lado, instituye el contralímite y, del otro lado, se refleja — en cuanto inspirado por los mismos valores constitucionales - en el ordenamiento europeo, hace que se resuelva correctamente el problema del lugar en el ordenamiento y del contenido material en los cuales, respectivamente, colocar e identificar la garantía preeminente de los derechos.

El ordenamiento de referencia para proteger los derechos de libertad es, como se ha dicho, uno de los ordenamientos de la integración y, en particular, el que aloja la axiología absorbente y dentro del cual se lleva a cabo la plena

50 Para una concepción según la que «de igual manera que ideales círculos concéntricos, en torno al "núcleo duro" de valores comunes a la Unión y a los Estados se teje, en cada ordenamiento nacional, una tela más larga, hecha de otros valores igualmente constitutivos del... «núcleo duro» del mismo ordenamiento, lo que nos da, en definitiva el contenido de la irrepetible identidad constitucional», cfr. A. RUGGERI, Valori e principi costituzionali degli Stati integrati d'Europa, en «Itinerari», XIII, cit., p. 220.

51 Sobre las relaciones entre el ordenamiento originario y los ordenamientos derivados y sobre todo el hecho de que la juridicidad de los ordenamientos derivados reside en una cualidad de relación cfr. M. PEDRAZZA GORLERO, Il patto costituzionale, cit., p. 111 y ss. 
protección de tales derechos ${ }^{52}$. Esto no equivale a descartar el concepto de libertad como un concepto de relación entre el área declarada libre y los límites que se le imponen. Sólo quiere poner de relieve que la garantía de las libertades no se puede descomponer por áreas del ordenamiento, es decir, que un ámbito de tutela sea confiado a un ordenamiento, y un ámbito ulterior a otro ordenamiento, y afirmar — sin embargo — que la misma libertad conoce límites diferentes y diferentes puntos de integración entre libertad y límite según el ordenamiento en el que se considere. Por lo tanto, teóricamente no tiene ningún sentido, o tiene un relieve extrínseco, hablar de un «mínimo estándar» garantizado por el ordenamiento europeo o el TEDH y de un «plusvalor» garantizado por el ordenamiento de los Estados miembros, con el fin de dar fundamento a concepciones «estadiales» o «multinivel» de las garantías de las libertades ${ }^{53}$. Lo que aparece como una etapa o nivel de protección no es más que el resultado de la material superposición entre las diferentes formas de garantía ofrecidas por varios ordenamientos, sus áreas de coincidencia y de diferenciación, prestándose a ser observadas como los sucesivos pasajes de una tutela graduada de la misma libertad.

Si se toma en consideración, por ejemplo, la libertad religiosa, tiene, en el ordenamiento europeo (artículo 10 de la Carta de Derechos Fundamentales), una esfera de extensión que, en lo que respecta al contenido, corresponde al área de las llamadas libertades negativas: libertad de no adherirse a ninguna religión, libertad de proclamar el propio credo religioso sin intromisiones arbitrarias de los poderes públicos, etc., en definitiva, una «libertad frente a ${ }^{54}$. En el ordenamiento italiano, por el contrario, abarca también un área po-

${ }^{52}$ Cfr. supra, $\S 2$.

53 Para el sentido de que la Carta de los derechos fundamentales de la Unión Europea es el «mínimo común denominador» con referencia al nivel de protección supranacional cfr. M. PATRONO, La Carta dei diritti fondamentali dell'Unione europea: un passo avanti verso l'Europa unita, en Legittimare l'Europa. Diritti sociali e crescita economica, a cargo de L. Barca y M. Franzini, Bolonia 2005, p. 147 En el sentido de que «el TEDH opera como factor de unificación interno para un núcleo mínimo inderogable de derechos dirigido a todos los Estados adhirientes» cfr. M. CARTABIA, Sub art. 53, en L'Europa dei diritti, cit., p. 363. Sobre las concepciones multinivel de la tutela de los derechos cfr. E. DE MARCO, La tutela «multilivello» dei diritti: punti di crisi, problemi aperti momenti di stabilizzazione, en La tutela multilivello dei diritti. Punti di crisi, problemi aperti momenti di stabilizzazione, a cargo de P. Bilancia e E. De Marco, Milán, 2004, p. 140 y ss.; F. SORRENTINO, La tutela multilivello dei diritti, en Rivista italiana di Diritto Pubblico Comparato. 2005, p. 79 y ss.

${ }^{54}$ Sobre este punto cfr. T. GROPPI, sub art. 10, in L'Europa dei diritti, cit., p. 97 según la que respecto a los ordenamientos nacionales y al TEDH «la cláusula limitativa del artículo 52 de la Carta comporta un límite más intenso, que toca también la libertad de pensamiento, de conciencia y religión y no la sola manifestación de esta última». 
sitiva que incluye la propaganda y el proselitismo, que es una libertad positiva, una «libertad de». El ordenamiento italiano prevé, en el artículo 19 de la Constitución, un área no garantizada por el ordenamiento europeo, concretando un plus de protección, un plusvalor respecto al valor supranacional limitado a la libertad negativa ${ }^{55}$.

Esto no se logra como resultado de una distribución de áreas de competencia en la tutela, que asignaría la mayor protección al ordenamiento no preeminente, sino porque en cada ordenamiento de libertad tiende autónomamente a lograr la garantía más elevada, el más alto punto de integración entre el área activa y límite, límite que se extiende desde la incidencia más baja y por lo tanto, la máxima protección del derecho hasta la no desnaturalización del mismo, es decir el respeto de su contenido esencial.

En el ordenamiento interno es el derecho de libertad en su integridad el que se erige como contralímite de la limitación de la soberanía proveniente de la Unión Europea. Sin embargo, dado que el derecho de libertad se descompone en un área activa intangible y en un área que se extiende del confín de ésta al de la máxima garantía, viniéndose a practicar, dentro de esta última, las limitaciones y compensaciones que fijan el punto de integración, es al núcleo esencial del derecho al que hace referencia el artículo 11 de la Constitución al examinar como contralímite, en cuanto necesario para el logro de la igualdad, la paz y la justicia, el mismo derecho. Por tanto, será el núcleo esencial de la libertad el que asuma la naturaleza y la función de contralímite ${ }^{56}$.

En el ámbito del ordenamiento jurídico europeo la tutela del derecho de libertad opera del mismo modo, extendiéndose desde el mínimo garantizado hasta el máximo punto de integración, «grandezas» que tenderán a coincidir, ya sea porque la igualdad, la paz y la justicia que constituyen el filtro de valores de los contralímites en el ordenamiento interno no podrán dejar de operar en el ordenamiento europeo, edificado para conseguir esos objetivos, como límites de su acción, ya sea porque la remisión a los principios fundamentales y la identidad constitucional de los Estados efectuada por el artículo 4.2 TUE, como medida del tratamiento europeo de los derechos fundamentales, dejan todavía al artículo 11 de la Constitución la valoración relativa a la naturaleza y a la amplitud de

55 M. RICCA, sub art. 19, en Comm. cost., a cargo de R. Bifulco, A. Celotto, M. Olivetti, I, cit., p. 426 y ss., 433 y ss.

56 Para una reconstrucción de la relación libertad-límite que identifica en el contorno «fijo» el contenido esencial del derecho y de la inherencia a este límite de la no desnaturalización del derecho, cfr. M. PEDRAZZA GORLERO, La costruzione, cit., p. 575. 
los contralímites de los derechos eventualmente afectados tanto en el núcleo esencial como en la protección «extensa».

Un problema puede surgir con respecto a la protección de los derechos sociales, que, evocando la necesidad de la prestación, se conforman de modo estructuralmente diverso respecto a los clásicos derechos de libertad negativa y positiva $^{57}$. De hecho, mientras la tutela de los derechos de libertad no es susceptible de ser condicionada, en el contenido esencial, el derecho social soporta que su Wesensgehalt (contenido esencial) deba someterse, si no a bieneslímite constitucionalmente protegidos, sí a criterios de compatibilidad y sostenibilidad económica y financiera. Basta pensar en las técnicas de ponderación desigual, hechas propias por el Tribunal de Justicia (sentencias Laval ${ }^{58}$ y Viking 59 en 2007), donde, por ejemplo, puede hablarse de derecho de huelga sólo en los casos en que se plantea como una prerrogativa caracterizada por el respeto a la proporcionalidad y necesidad de la acción colectiva adoptadas, a fin de no atentar contra la libertad de circulación de mercancías, capitales, servicios, proveedores de trabajo y la competencia. En última instancia, el contralímite que asume como propio el contenido los derechos sociales, puede ceder con mayor facilidad que el contralímite que ser erige como protector del núcleo esencial de los derechos de libertad.

El artículo 11 de la Constitución muestra aquí un valor potencialmente reversible: por un lado, contribuye a la formación del filtro de valoración de los principios que se oponen como contralímites; por otro lado, muestra una peculiar actitud integrativa, como sucede cuando la Unión Europea, en el ejercicio de sus propias competencias normativas, lleva a cabo un limitación del derecho social que incide sobre el núcleo esencial del mismo.

No parece que pueda asumirse sin embargo la posición según la cual el criterio de la compatibilidad financiera de las prestaciones de tales derechos, que desciende de los vínculos asumidos a nivel europeo mediante la firma del Pacto

57 En este sentido cfr. A. PACE, Problematica, cit., p. 148, para el que «la circunstancia de que el pleno ejercicio de los derechos de libertad reclame, tal vez, la intervención del legislador... y el hecho relevante de que también los derechos de libertad presuponen en cualquier caso la existencia de estructuras públicas... de garantía no deben hacer olvidar que la diferencia de los derechos de libertad con relación a los derechos sociales es estructural y no es históricamente mutable».

58 Cfr. Corte giust., 18 dicembre 2007, c.-341/05, sent. Laval un Partneri Ltd contra Svenska Byggnadsarbetareförbundet, Svenska Byggnadsarbetareförbundets avdelning 1, Byggettan e Svenska Elektrikerförbundet, en Raccolta, 2007, p. I-11767.

59 Cfr. Corte giust., 11 dicembre 2007, c.-438/05, sent. International Transport, Finnish Seamen's Union contra Viking Line ABP, Ö̈ Viking Line Eesti, en Raccolta, p. I-10779 y ss. 
de Estabilidad y Crecimiento ${ }^{60}$, se presente como una forma de condicionamiento de esos derechos a nivel nacional.

Si bien es cierto que la reducción gradual de los déficit públicos obliga a adoptar medidas de contención el gasto, no es menos cierto que, como se ha dicho, el núcleo esencial de los derechos sociales está integrado en el mecanismo normativo diseñado por el artículo 11 de la Constitución y, como tal, puede activar los contralímites en los casos en que el derecho objetivo europeo incida, limitándolos, sobre tales derechos. Dicho de otro modo: habría una segura fisura del principio del Estado democrático y social de derecho, que cualifica, como principio de estructura, la forma política de los ordenamientos constitucionales nacionales, entre ellos el italiano ${ }^{61}$.

Parece más razonable suponer que el criterio de la compatibilidad financiera —o, más precisamente, el principio de la sostenibilidad de los costes de las prestaciones de los derechos sociales - es ahora constitutivo del núcleo esencial de los mismos. El enfoque tiene la ventaja, en primer lugar, de no exceptuar el núcleo de las situaciones jurídicas subjetivas de prestación que constituyen una de las más relevantes conquistas del constitucionalismo democrático y social ${ }^{62}$ representativas, por lo demás, de la forma de Estado de los países miembros de la Unión Europea. En segundo lugar, justifican la opción tomada por la Carta de Derechos Fundamentales de la Unión Europea, de la llamada indivisibilidad de los derechos ${ }^{63}$, recogidos no según las tradicionales nomenclaturas, sino en términos de valores — con el resultado de que los derechos sociales se clasifican de modo diverso bajo los valores de la libertad (por ejemplo, el derecho a la educación: artículo 14 de la Carta, la libertad profesional y derecho al trabajo: artículo 15), de la igualdad (por ejemplo, la no discriminación: artículo 21) y de la so-

60 Sobre el Pacto de Estabilidad y Crecimiento, introducidos por los reglamentos n. 1466/97/CE e n. 1647/97/CE, cfr. G. CAPORALI, Patto di stabilità ed ordinamento europeo, en Dir. soc., 2004, p. 83 y ss. Sobre las innovaciones aportadas al Pacto de Estabilidad por los reglamentos n. 1055/05/CE e n. 1056/05/CE cfr. M. BARBERO, Il nuovo patto europeo di stabilità e di crescita alla prova dei fatti: i recenti casi di Francia, Germania e Italia, en Rivista italiana di Diritto Pubblico Comparato, 2007, p. 1315 y ss.

${ }_{61}$ Sobre este punto cfr. A. BALDASSARRE, Diritti sociali, en Enc. giur., XI, Roma, 1989, p. 1 y ss.; L. CAR-LASSARE, Forma di Stato e diritti fondamentali, en Quaderni costituzionali, 1995, p. 34. Sobre valores constitucionales de la forma de Estado italiana cfr. C. MORTATI, Istituzioni di diritto pubblico, Tomo I, a cargo de F. Modugno, A. Baldassarre e C. Mezzanotte Padua 1991, p. 151 y ss.

62 Para un estudio de la Constitución de Weimar como laboratorio jurídico-político de la forma de Estado democrático-social cfr. F. NEUMANN, Il diritto del lavoro fra democrazia e dittatura, Bolonia, 1983, p. 121 y ss.

63 Sobre el concepto de indivisibilidad de los derechos en la Carta cfr. C. PINELLI, Il momento della scrittura. Contributo al dibattito sulla Costituzione europea, Bolonia 2002, p. 215 y ss. 
lidaridad (por ejemplo, el derecho de los trabajadores a la consulta dentro de la empresa: artículo 27, la protección de la salud: artículo 35)—. Por último, porque la inherencia del criterio de compatibilidad y sostenibilidad financiera al núcleo esencial del derecho social permite el equilibrio «interno» al mismo Wesensgehalt, que no sólo no exceptúa el contenido del derecho de prestación, sino que confía la protección a las mismas Cortes de la integración europea. En otras palabras: el carácter recesivo, financieramente establecido, de los derechos sociales no podrá aplicarse hasta el punto de exceptuar su propio contenido.

\section{LA FORMA CONDICIONANTE COMO MECANISMO NORMATIVO RESULTADO DEL ARTÍCULO 4, II, TUE Y DEL ARTÍCULO 11 DE LA CONSTITUCIÓN. EL DIÁLOGO ENTRE LA CORTE DE JUSTICIA Y LA CORTE CONSTITUCIONAL EN LA ELABORACIÓN DE LA IDENTIDAD CONSTITUCIONAL NACIONAL COMO «CONTRALÍMITE INTEGRADO»}

Por otro lado, hay que tener presente que, como señalamos anteriormente, el artículo 11 de la Constitución, por una parte, abarca el Wesensgehalt (contenido esencial) del derecho fundamental como elemento constitutivo del filtro de compatibilidad del derecho objetivo europeo con los principios constitutivos de la identidad constitucional nacional y, por otro lado, genera el ordenamiento europeo como ordenamiento derivado pero prevalente sobre el ordenamiento italiano, transmitiendo a aquél los objetivos de paz y justicia como expresivos de la misma axiología, por lo que no parecerá un inútil ejercicio determinar si en el Derecho de la Unión opera un mecanismo normativo que desplaza la forma condicionante de los principios del régimen de los ordenamientos constitucionales.

Esto, sin embargo, parece ajustarse a las necesidades de un proceso de integración que, desde la sentencia Costa c. ENEL ${ }^{64}$, delinea la propia evolución en la

${ }^{64}$ Cfr. Corte Costituzionale, sentencia de 15 julio 1964, c. 6/64, Costa c. E.N.E.L., en Raccolta, 1964 , p. 1144 y ss. En tal decisión los jueves comunitarios han configurado el ordenamiento comunitario como integrado en el de los Estados miembros y prevalente sobre estos. Los Estados habrían «limitado, aunque sea en campos determinados, sus poderes soberanos y creado ... un complejo de derecho vinculante», con la consecuente «imposibilidad ... de hacer prevalecer, contra un ordenamiento jurídico aceptado por ellos en condiciones de reciprocidad, un proceso unilateral ulterior», que no sería oponible, por tanto, al ordenamiento común. Para F. DONATI, Diritto comunitario e sindacato di costituzionalità, cit., p. 199, existen «obstáculos de naturaleza insuperable que impiden la aceptación de la tesis sostenida por la Corte de Justicia». Esta —que se funda sobre la idea de una «limitación definitiva» de la soberanía estatal— reconoce a los Tratados el «rango de 
dirección de una disposición ordinamental caracterizada por «poderes autónomos y propios» ${ }^{65}$. Por otra parte, un ordenamiento que se propone como realidad institucional autolegitimada ${ }^{66}$ requiere un parámetro autónomo de legitimidad de los actos que inciden sobre los principios constitucionales nacionales comunes a la axiología de la integración. No una mera Reflexwirkung de las axiologías estatales, sino una disposición que positivamente haga activable el contralímite, ya a nivel europeo, por parte del Tribunal de Justicia, llamado, de conformidad con el artículo 19, párrafo 1, apartado I, TUE, a controlar la legitimidad de los actos europeos emanados en violación de los Tratados europeos.

Parece posible afirmar que la forma condicionante — que incorpora la axiología absorbente - se encuentra, a nivel europeo, en el artículo 4 TUE, introducido por el Tratado de Lisboa, allá donde se establece el respeto a la identidad constitucional de los Estados miembros «situada en su estructura fundamental, política y constitucional», como «depósito», concretamente justiciable en sede jurisdiccional por parte del Tribunal de Justicia, de los derechos «identitarios» estatales.

Ya a nivel europeo, por lo tanto, en la operación de delimitación subyace un filtro de compatibilidad de los valores, custodiada por el Tribunal de Justicia. Resta el hecho de que el parámetro de compatibilidad reside en el respeto de las identidades constitucionales de los Estados miembros ${ }^{67}$, supervisadas, a su vez, por los Tribunales Constitucionales nacionales.

La concreción del alcance de tal identidad no parece, sin embargo, definible sólo por el Tribunal de Luxemburgo. Ciertamente, habrá casos en los que la posición del filtro de valores, derivados de artículo 4 del TUE, se hará interpretando la disposición conforme a los principios fundamentales de las Constituciones nacionales. No obstante, no parece posible limitar el alcance de la disposición a mero «principe d'interprétation du droit communitaire», con objeto de verificar si subsiste «la violation ... des principes fondamentaux de l'ordre constitutionnel

una Constitución federal», a la que subordinar las constituciones nacionales, cosa que, a la luz de los hechos, parece que no se puede compartir. Según S. CASSESE, L'influenza del diritto amministrativo comunitario sui diritti amministrativi nazionali, en Rivista Italiana di Diritto Pubblico Comparato, 1993, p. 335, la Unión sería transformada en «un poder público con las mismas obligaciones de los Estados». Nacida como organización de finalidad económica, se habría convertido en "plurisectorial... más allá del área de la economía». Cfr. Entre otros J.H.H. WEILER, La Costituzione dell'Europa, Bolonia, 2003, p. 391 y ss.

65 A. MANZELLA, Lo Stato «comunitario», cit., p. 291.

${ }^{66}$ Cfr. A. D'ATENA, Le Regioni italiane, cit., p. 3 y ss.

67 Sobre este punto cfr., M. CARTABIA, «Unità nella diversità»: il rapporto tra la Costituzione europea e le costituzioni nazionali, en Dir. un. eur., 2005, p. 593. 
par un acte communautaire et interpréter le droit communautaire dans le respect de la Constitution nationale de manière à en éviter la violation» ${ }^{68}$. Esto, de hecho, significaría, por una parte, asimilar los contralímites a las tradiciones constitucionales comunes, resolviendo los primeros en las segundas; y por otra parte, atribuir al Tribunal de Justicia la tarea de diseñar, más allá de las tradiciones, las mismas identidades constitucionales, que se elaborarían así con el riesgo de que se seleccionasen aquellos elementos que interesen al Tribunal europeo ${ }^{69}$.

La forma condicionante, al delinear las identidades constitucionales, no puede dejar de abrirse al diálogo con los Tribunales Constitucionales de los Estados miembros. Se trata de una extensión a los derechos fundamentales de una intuición ya formulada por la doctrina con referencia al principio de subsidiariedad. Como se ha sostenido, puesto que «el reparto constitucional de las competencias entre Estado y Regiones denota la identidad constitucional de los Estados miembros, no parece impropio pensar que, con objeto de verificar el respeto de tal reparto en aplicación del principio de subsidiariedad, pueda acudirse, por parte de la Corte Costituzionale, al instituto de la cuestión prejudicial» ${ }^{70}$. En relación con la tutela de los derechos fundamentales, de hecho, la cuestión prejudicial es instrumento mediante el que se examina el alcance — y la validez- de los actos comunitarios que inciden sobre los derechos constitucionales «identitarios», «con objeto de valorar la compatibilidad con tales identidades, que son elevadas, al mismo tiempo, a parámetros nacionales y europeos de los objetivos de la integración supranacional» ${ }^{71}$.

Hay que recordar que la forma condicionante puede adoptar también el ropaje de la decisión jurisdiccional, por lo que se puede considerar que del «filtro

68 M.-C. PONTHOREAU, Identité constitutionnelle et clause européenne d'identité nationale. L'Europe à l'épreuve des identités constitutionnelles nationales, en Diritto Pubblico Comparto ed Europeo, 2007, p. 1584.

69 A. RUGGERI, Fonti, norme, criteri ordinatori. Lezioni, Turín 2005 p. 232.

70 M. NICOLINI, Partecipazione regionale, cit., p. 225, para el que «la proposición de la cuestión prejudicial parece poder contribuir sea a verificar... la compatibilidad de los actos de ejercicio de las competencias regionales con los principios comunitarios — con la consecuencia que el Tribunal de Justicia ejercitaría un control "indirecto" sobre los actos legislativos nacionales—, sea a provocar un pronunciamiento sobre la interpretación —o sobre la validez- de los actos comunitarios que afectan a las materias de competencia regional en relación a la subsistencia de los presupuestos para el ejercicio subsidiario de las competencias comunitarias, valorando, a la luz de los principios constitutivos de las identidades constitucionales de los Estados miembros, la idoneidad de las Regiones para conseguir los objetivos de la integración supranacional».

${ }^{71}$ M. NICOLINI, Il livello integrale di tutela come contenuto indefettibile dello statuto sovranazionale dei diritti fondamentali, en PEDRAZZA GORLERO, M.(ed.), Corti costituzionali e Corti europee dopo il Trattato di Lisboa, Nápoles, 2010, § 9. 
de compatibilidad» de la identidad constitucional —o mejor, de la percepción que de tal identidad tiene el ordenamiento europeo- participan las jurisdicciones supranacionales y constitucionales. La delimitación del contenido de aquella identidad constitucional que, en el sentido del artículo 4 TUE es autolímite puesto por el ordenamiento europeo en relación con su primacía, sitúa como central la exigencia de que a los mismos Tribunales Constitucionales, creadores y depositarios del contralímite, no se les sustraiga la facultad de participar, con el Tribunal de Justicia, a la determinación de aquello que está excluido a la eficacia del derecho objetivo europeo.

Con el fin de evitar que la identificación del contralímite, bajo la forma europea de la identidad constitucional, sea monopolizada por el Tribunal de Justicia, es oportuno elaborar mecanismos entre los ordenamientos mediante los cuales se garantice el carácter vinculante de las sentencias de las jurisdicciones constitucionales en orden al reconocimiento de los principios y derechos que contribuyen directamente a componer la misma identidad constitucional reclamada por el artículo 4 del TUE. Un ejemplo se puede extraer del mecanismo de la interposición integrativa de las decisiones del TEDH respecto del parámetro de legitimidad constitucional, como demuestran las sentencias número 348 y 349/2007 de la Corte Costituzionale italiana. Este mecanismo podría replicarse precisamente para coordinar la relación entre el art. 4 del Tratado y el art. 11 de la Constitución, o bien vincular la determinación, por parte de la Corte de Justicia, de los elementos que componen la identidad constitucional nacional en relación con lo que los Tribunales Constitucionales califican como intocable al ser representativo de los derechos y principios fundamentales del ordenamiento constitucional.

En última instancia, la identidad constitucional nacional se inserta en el mecanismo normativo diseñado por el artículo 11 de la Constitución y por el artículo 4 del TUE, es decir, en la forma condicionante establecida por la participación paritaria de las normas constitucionales nacionales y europeas, según la interpretación del Tribunal Constitucional y del Tribunal de Justicia, para la formación de un contralímite integrado ${ }^{72}$, puesto que, aunque se encuentra en más de un sistema, desempeña el papel y el grado de protección a los que da forma el proceso de integración. Esta interpretación tiene el mérito de evitar el riesgo de que las relaciones entre los Tribunales Constitucionales nacionales y el Tri-

72 Según la terminología sugerida por Daniele Butturini en una conversación personal y que desarrolla más ampliamente en D. BUTTURINI, La partecipazione paritaria della Costituzione e della norma sovranazionale all'elaborazione del contenuto indefettibile del diritto fondamen-tale. Osservazioni a margine di Corte cost. n. 317 del 2009, en Giur. cost., 2009, p. 1822 y ss. 
bunal de Justicia se caractericen como formas de jerarquía en las cuales prevalezca el segundo sobre los primeros y de asociar a los Tribunales Constitucionales a la elaboración del contralímite integrado, promoviendo eventualmente cuestiones prejudiciales, formuladas por las mismos Tribunales Constitucionales, idóneos para vincular al juez europeo con la concepción nacional de la relativa identidad constitucional.

\section{Title}

The search for the «forma condizionante». Introduction to the relations between national constitutional courts and europeans courts after the treaty of lisbon

\section{Sumary}

1. Relations between the courts, integration between systems and «shape determinant» in relation to the protection of fundamental rights. 2 . Guarantee of fundamental rights in the systems integration: axiology conditioning absorbent and form. The thesis that substantial axiology preeminent individual regardless of membership in the organization and the formal quality. Criticism. 3. The inherent constraint of the form needed to axiology absorbent. Demonstrations of how conditioning: the normative acts. Judgments and conditioning attenuated form. 4. Substantial conception and overcoming the theory of counterlimits. Criticism: hierarchy between the fundamental principles of open or excluded constitutional revision. The principle of rigidity superprinciple instrumental in establishing a hierarchy between them. Article 11 of the Constitution as opening clause integration preserves the hierarchy of fundamental constitional principles in relation to the european law. 5. Equality, peace and justice among nations. Article 11 of the Constitution as fundamental superprinciple regulator the hierarchy of domestics constitutional principles relied on european integration. Does article 11 of the Constitution as an exercice of sovereignty or carrying axle of constitutional democracy? 6 . Comprehensive custody of fundamental rights in any of the regulations of integration conceptions versus «stadials» or multilevel security of right. The counterlimits as guardianship of the core fundamental rights. 7. The shape determinant as regulatory mechanism a determinant result of article 4, II, TUE and 11 of the Constitution. The dialogue between the Court and the Constitutional Court in the elaboration of national constitutional identitity as «integrated counterlimit».

\section{Resumen}

El objetivo de este trabajo consiste en analizar las relaciones entre los Tribunales Constitucionales de los Estados miembros de la Unión Eu- 
ropea y los Tribunales Comunitarios tras la entrada en vigor del Tratado de Lisboa, particularmente en lo que respecta a la tutela de los derechos fundamentales de los ciudadanos de los países miembros e incidiendo en la jerarquía del ordenamiento comunitario frente a los ordenamientos juridicos nacionales.

\section{Abstract}

The aim of this article is analize the relations between the Constitutional Courts of the states of European Union and the European Courts, after coming into effect the Lisbon Treaty, particularly referring to the protection of the EU citizens' fundamental rights, and with a special focus on the hierarchy of the European legal ordinance, in contrast with the legal ordinance of the EU states.

\section{Palabras clave:}

Union europea, Tratado de Lisboa, Derechos fundamentales, Contralímites, Diálogo entre Tribunales nacionales y europeos.

\section{Key words}

European Union, Treaty of Lisbon, Fundamental Rights, Counterlimits, Judiciary dialogue among national and European Courts of Law. 
